\title{
La voluntad ciega de Las ciegas hormigas: de Schopenhauer y Nietzsche a (Unamuno, Baroja) Pinilla
}

\author{
María EnCARnación Pérez Abellán \\ I.E.S. Melchor de Macanaz
}

Resumen: Las ciegas hormigas (1960), primera novela de Ramiro Pinilla, actualiza las claves de la narrativa vasca barojiana y unamuniana de pensamiento existencialista decimonónico. La confrontación irreconciliable entre el noúmeno y el fenómeno schopenhaueriano, devenidos en voluntad ciega y voluntad de poder nietzscheana, enlaza discursiva, pero también estilísticamente, con sendos escritores precedentes a partir de las peripecias de los vecinos de Algorta. Pinilla podrá, además, fundir ambos planteamientos con las formas de la tragedia clásica, pues las fuerzas nouménicas absurdas son fatum irrevocable, hamartías sucesivas e hybris contrapuesta a toda areté, cernido todo sobre la estirpe castigada de los Jauregui.

Palabras clave: Noúmeno, Schopenhauer, Nietzsche, Ramiro Pinilla.

The blind will of Las ciegas hormigas: from Schopenhauer and Nietzsche to (Unamuno, Baroja) Pinilla

Abstract: The Blind Ants (1960), first Ramiro Pinilla's novel, brings to the present the keys of the Vasque narrative about nineteenth existencialism Baroja and Unamuno's thoughts. Noumeno and phenoumeno -Schopenhauer's concepts- are opposite, but both of them become into blind and power will (exposed by Nietzsche). They are also connected with the narrative of the Spanish authors, thanks to the facts starred by the citizens in Algorta. Pinilla will develop, in addition, the greek or classical tragedy forms, because noumenic strength is fatum or destiny, hamarties and hybris (completely different from right arête), all of them over the punished Jauregui's family.

Keywords: Noumenos, Schopenhauer, Nietzsche, Ramiro Pinilla. 


\section{INTRODUCCIÓN}

¿Quién puede saber para qué han sido creadas así?

(Pinilla, 2014: 306)

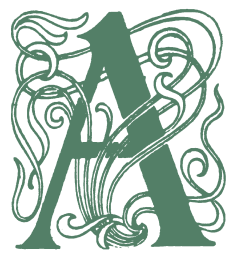

veces se irrumpe en el mundo de ficción y vida que es la Literatura con una ópera prima que rebasa su calidad inicial de tarjeta de presentación por plantear no sólo las constantes futuras del autor, también el sesgo de una tradición que lo precede y que ha sabido asumir con autonomía. Las ciegas hormigas, la primera novela ${ }^{1}$ de Ramiro Pinilla (1960) es uno de estos casos: posee las claves del universo particular por el que el autor continuará transitando en Verdes valles, colinas rojas (2004-2005), los relatos ${ }^{2}$ o La higuera (2006), amén de presentarse, deliberada o intuitivamente, como obra deudora -cuando no continuadora implícita- de un posicionamiento vital y literario contenido ya en Unamuno o Baroja, vascos como él y siempre lectores de profunda asunción de las directrices filosóficas de Schopenhauer y Nietzsche. Pinilla se aproximaba en ella hasta los planteamientos del primer Existencialismo compartido con los maestros del Noventa y ocho, y reflexionaba -vía personajes- sobre la voluntad de vivir humana en pugna irracional (e irremisible) con la voluntad ciega nouménica y schopenhaueriana, sin obviar que este mismo y primer acto de la voluntad alumbrará la definitiva y última (voluntad) de poder con que Nietzsche superaba al primero.

Pinilla, pilar de la nueva narrativa vasca de la segunda mitad del siglo XX, ingresaba así en la nómina de autores de la tierra ceñidos por cierto aire de familia conceptual, pues los planteamientos existenciales transferidos a las

\footnotetext{
1 En realidad, Las ciegas hormigas venía precedida por sendas publicaciones consideradas menores por el propio Pinilla: El misterio de la pensión Florrie, publicada en Bilbao por Editorial Moderna en 1944 bajo el seudónimo de Romo P. Girca, y El ídolo, también publicada en Bilbao en 1957 por entregas en la revista "El Mensajero" de la Universidad de Deusto. El autor y la crítica preferirían no obstante, como título detonante de la larga trayectoria bibliográfica del primero, la novela que nos ocupa, galardonada el mismo año de su publicación con el Premio Nadal y un año más tarde (1961) con el Premio de la Crítica.

2 Los cuentos del autor fueron recopilados por la editorial Tusquets en 2011 bajo título homónimo, colección en la que no se encuentran La gran guerra de doña Toda (1978) o Andanzas de Txiki Baskardo (1979). Previamente, habían aparecido en dos colecciones parciales e independientes, la primera titulada Recuerda, oh, recuerda, publicada en 1975 por Ediciones del Centro y dos años más tarde Primeras historias de la guerra interminables, ya con sello de Luis Haranburu Editor.
} 
ciegas hormigas metafóricas lo alineaban junto a Baroja con las disyuntivas de Manuel Alcázar en La busca y Mala hierba (ambas de 1904), o su Iturrioz y Andrés Hurtado en El árbol de la ciencia (1911), pero también junto al Unamuno nivolista y autor de ensayos. De este modo, el escritor, que reconoce el magisterio que ejercieron sobre él Dickens o Twain, Faulkner y García Márquez, se aproxima a los renovadores de la prosa española de principios de siglo, ofreciendo una lectura que continúa ahondando en el hecho de que el delito mayor/ del hombre [sea] haber nacido3. Con Las ciegas hormigas Ramiro Pinilla transforma la tradición en universalidad de raíz calderoniana y ofrece un relato clásico al lector (entendido ya desde la significación nueva o resemantización que de lo clásico se origina en El ruido y la furia o en Absalón, Absalón, que nace al fin en el Faulkner que aúna lo ecuménico con la renovación formal hasta convertir en unidad indisoluble interdiscurso y texto con el que materializarse aquel).

\section{FE DE VIDA (Y PENÚLTIMAS VOLUNTADES). NOÚMENO Y FENÓMENO EN EL SIGLO XIX}

Pinilla (mediatizado por Baroja y Unamuno) parece partir del grueso filosófico alemán del siglo XIX y sus exponentes máximos Arthur Schopenhauer y Friedrich Nietzsche, quienes a su vez se remontaban necesariamente al Idealismo hegeliano, convertida la terna casi de inmediato en revulsivos del pensamiento clásico occidental. No resultará extraño, pues Nietzsche se conceptuaba no como hombre, sino como «dinamita» y «filósofo del martillo», eslabón en realidad (pen)último de una cadena de planteamientos previos a los que lograba superar partiendo del cuestionamiento del sentido vital humano, desasido ya de todo soporte divino. Schopenhauer, a quien lee ávidamente durante su juventud condicionando así su etapa romántica, había concluido asimismo en El mundo como voluntad y representación (1819) que era necesario resemantizar la realidad cognoscible desde el sufrimiento y el

3 El absurdo vital, que aherroja al hombre a carecer de fin a lo largo de su existencia y cuyo origen no es sino el hecho de nacer, lo sintetizan, en El mundo como voluntad y representación, los versos de Calderón: «El verdadero sentido de la tragedia es la profunda comprensión de que lo que el héroe expía no son sus pecados particulares sino el pecado original, es decir, la culpa de la existencia misma: "Pues el delito mayor | del hombre es haber nacido", como Calderón afirma expresamente» (Schopenhauer: 152). Significativo resulta, asimismo, el título que E. M. Cioran escoge para una de sus colecciones de aforismos: Del inconveniente de haber nacido (1973). 
dolor inherentes al desconocimiento que el hombre tiene de esa otra realidad no visible a los ojos y a la que, no obstante, habrá de sobreponerse.

Schopenhauer escindía la realidad en dos planos bien diferenciados: el de una nouménica, inmanente y ajena a toda acción del hombre cuyo código de funcionamiento intrínseco es autónomo, ciego e irracional, y una segunda fenoménica, fruto de la conceptualización personal que cada individuo lleva a cabo sobre todo lo percibido sensorial y racionalmente, a la que Unamuno calificaba como mundo «necesariamente subjetivo, humano, antropomórfico». Aunque ante éste, añadía, «siempre se levantará [...] el vitalismo, siempre la voluntad se erguirá frente a la razón» (Unamuno, 1999:132).

Sin embargo, ambas vertientes de esta realidad total o pánica no actúan de modo armonioso recíprocamente. La asincronía se establece al confrontar la ausencia de finalidad o utilidad que determine el flujo inextinguible de las fuerzas móviles nouménicas (que actúan per se, con plena autonomía óntica), a la pauta con la que el hombre sí trata en cambio de dirigir su representación del mundo, anhelando conceder a su existencia un propósito, revelado invariablemente como absurdo e insatisfecho por cuanto de juego o representación dramática entraña:

Pues se nos ofrece este curioso fenómeno: que la acción ciega de la voluntad y la iluminada por el conocimiento [...] se extienden una al terreno de la otra [...]. Por un lado encontramos que entre los actos de los animales guiados por el conocimiento intuitivo y sus motivos hay uno que carece de ellos y se efectúa con la necesidad de la voluntad ciega: se trata de los impulsos [...] que, no estando dirigidos por motivo ni conocimiento alguno, aparentan realizar sus obras incluso por motivos abstractos o racionales. [...] Por último, cuando la voluntad ha llegado al grado máximo de su objetivación [...] el ser del hombre, complicado, polivalente, dúctil, sumamente necesitado y expuesto a innumerables agresiones [...] tenía que estar iluminado por un doble conocimiento; [...] había que añadir al conocimiento intuitivo [...] la razón como capacidad de los conceptos abstractos. Con esta se daba la reflexión, la visión que abarca el futuro y el pasado, y, como consecuencia de ellas, la deliberación, la preocupación, la capacidad de obrar premeditadamente con independencia del presente y, finalmente, una conciencia plenamente clara de las decisiones de la propia voluntad. Ya con el simple conocimiento intuitivo surgía la posibilidad de la ilusión y el engaño (Schopenhauer: 96). 
La voluntad ciega que configura el movimiento universal no obedece más que a su propia esencia extrínseca al hombre, a éste se le hace inasumible y la conceptúa poética y trágicamente como destino, al tiempo que se le opondrá denodadamente, vía determinación y voluntad fenoménicas, en cada acto volitivo que lo conduzca a la recompensa gratificante. Ante ello, Schopenhauer advierte de la condición infatigable y totalmente tantálica de esta sucesión de deseos, pues por carecer a su vez de un fin último no habrá de ser vehículo para la obtención de la definitiva razón de ser vital. La aprehensión de que, en el fondo, el hombre y su vida no son sino accidentes aleatorios en la dinámica de fuerzas ${ }^{4}$ acarreará desesperación y angustia a aquéllos que, ajenos ya a lo trascendente, cuestionándolo o simplemente suspendiendo el juicio (como la abuela de nuestra novela instalada en la epojé tras la muerte de su nieto), logran penetrar este sinsentido de la existencia: «¿Qué es lo que sucede cuando el cuerpo que hemos soportado durante toda la vida deja de ser el manojo de pasiones vivas y se convierte en el espantoso muñeco inmóvil que nos llena de terror?» (Pinilla, 2014: 259).

¿Qué hacer y qué dirección tomar? La pregunta barojiana axial en El árbol de la ciencia (1911) se haría eco de la propuesta doble de Schopenhauer. Existencialismo pasivo y existencialismo activo son opciones para asumir; mientras que al primero le corresponde el horror de la toma de consciencia y la inacción que sólo desembocan en el vértigo y el suicidio, el segundo milita operativamente, asume la condición absurda de la existencia y trata de paliarla mediante el compromiso con el otro o la anulación de todo apego emocional, en un viraje hacia la espiritualidad oriental, específicamente la budista, ansiando la supresión del sufrimiento a través de la renuncia a toda relación entablada entre el yo y los demás, pero también entre el yo y el yo, en un ejercicio de despersonalización suprema que es nirvana o ataraxia clásica. Sólo estas dos últimas podrán salvar al hombre de la desorientación que conllevan las reflexiones críticas que torturaron a Segismundo. La voluntad de vivir insta a revertir el absurdo de estar diseñada para ejecutar arbitrariamente unos hechos sin que obedezcan a ninguna trascendencia, y por ello el hombre se autoimpone metas y pautas que lo convierten en no más que un autómata, actuando porque así ha de ser, aunque sin pre-

4 A tal respecto, apunta irónicamente Cioran décadas más tarde: «Sé que mi nacimiento es una casualidad, un accidente risible, y, no obstante, apenas me descuido me comporto como si se tratara de un acontecimiento capital, indispensable para la marcha y el equilibrio del mundo» (Cioran, 2014: 10). 
venirse de lo paradójico de éstas. El hombre debería despojarse de todas ellas e indagar tan sólo en sí, pero para esto habrá que aguardar al filósofo-dinamita. Hasta entonces, el hombre actuará como las hormigas ciegas, que construyen largas hileras para el transporte y aprovisionamiento del hormiguero, determinadas para no hacer cosa alguna más pero incapaces -también- de analizar su comportamiento porque no ven. Hormigas que «[...] tropiezan y se levantan. Están preparadas para vencer todo lo que les pongan delante [...] Han sido creadas con esa consigna y la cumplen» (Pinilla, 2014: 306). Como los recogedores de carbón del barco despanzurrado frente a las costas de Algorta ${ }^{5}$, que son impelidos mecánicamente para recoger los restos desperdigados por las rocas con la intención confesa de aprovisionarse ante el invierno crudo (firmes en su voluntad fenoménica), pero con el convencimiento de que de nada servirá su esfuerzo, pues todo les será incautado y habrá sido en vano su trabajo (derrotados de antemano por la incontrolada nouménica). Habrá dado comienzo el relato de sendas voluntades, y aun una tercera, la de poder, a través del pulso a las primeras que Sabas Jauregui presenta, también en consonancia con la línea de pensamiento orteguiano que insta a conferir sentido a la existencia propia desde la autonomía individual, aun cuando pueda ésta contraponerse a las propuestas paralelas de sentido (o absurdo) vital en el otro. Porque Sabas podrá hacer suyo el hecho de que:

La vida [...] nos es dada vacía. Queramos o no tenemos que llenarla por nuestra cuenta; esto es, tenemos que ocuparla de este o del otro modo. Por ello la sustancia de cada vida reside en sus ocupaciones. Al animal no sólo le es dada la vida, sino también el repertorio invariable de su conducta, Sin intervención suya, los instintos le dan ya resuelto lo que van a hacer y evitar. [...] Su vida no ha estado vacía, indeterminada. Pero el hombre es un animal que perdió el sistema de sus instintos [...] Al encontrarse existien-

\footnotetext{
5 Salvo en el universo de ficción autónomo creado por Pinilla, Algorta no posee, geográfica o administrativamente, entidad propia. Pinilla extrae este barrio real del municipio de Getxo para hacerlo depositario de unidades de sentido espacial y narrativo extensivas no sólo a Las ciegas hormigas, también a Verdes valles, colinas rojas (2004-2005 en editorial Tusquets) o Aquella edad inolvidable (2012). La geografía en la que Pinilla ubica habitualmente sus tramas y personajes surge de la adaptación del espacio real y pragmático vasco a las necesidades estéticas y significativas de la ficción que necesariamente han de trascender el mero valor locativo de aquél. María Bengoa Lapatza-Gortazar indica a propósito del proceso de recreación visual (y geográfica) de Verdes valles, colinas rojas (y a modo de anécdota) que: «Tuve el privilegio de dibujar también los caseríos, el molino, la venta, el verdadero Roble de los vascos... todo lo que Ramiro me dictó sobre un gran mapa inmaculado de Getxo para hacer coincidir su mundo imaginario con el escenario real» (Acillona, 2015: 12).
} 
do se encuentro ante un pavoroso vacío. No sabe qué hacer; tiene él mismo que inventarse sus quehaceres y ocupaciones [...] no hay más remedio que escoger un programa de existencia (Ortega y Gasset, 1943: 421).

\section{VOLUNTAD DE VIVIR PARA HORMIGAS CIEGAS, VOLUNTAD DE PODER PARA SABAS JAUREGUI}

En Las ciegas hormigas convergen ambas voluntades filosóficas, asumidas previamente por Baroja y Unamuno en sus obras, predecesoras de ésta. Hasta Pinilla llegan las pesquisas del primero a propósito de la voluntad humana postuladas a través del tío Iturrioz y el joven Andrés en «Inquisiciones»

[...] no somos un intelecto puro, ni una máquina de desear, somos hombres que al mismo tiempo piensan, trabajan, desean, ejecutan...Yo creo que hay ideas que son fuerzas [...] Eso que usted llama fe no es más que la consciencia de nuestra fuerza. (Baroja, 1993: 179-181).

Mientras sobre las hormigas planea, por parte del segundo, el convencimiento de que tampoco:

[...] la razón nos da aliciente y consuelo de vida y verdadera finalidad de ésta [...] en el fondo del abismo se encuentran la desesperación sentimental y volitiva y el escepticismo racional frente a frente, y se abrazan como hermanos. Y va a ser de este abrazo $[\ldots]$ trágico $[\ldots]$ de donde va a brotar [...] una vida seria y terrible [...] De continuo la voluntad [buscará] absorber al mundo en nosotros, apropiárnoslo [...] la voluntad es egoísta (Unamuno, 1999: 130).

La novela bascula en realidad sobre ambos pivotes contrapuestos: la determinación atroz, pero absurda en igual medida, somatizada por las gentes anónimas del pueblo, conscientes del trabajo inane al que expondrán sus vidas, y esa misma determinación, reconvertida en triunfo -circunstancialdel protagonista Sabas Jauregui, poseedor de una actitud combativa que lo eleva sobre el pesimismo abnegado de sus paisanos por pretender derrotar él, no sólo al destino que se empeña en reducirlos a la condición de hormigas, también a las propias reglas que lo desafían pero se hallan condenadas al fracaso. Sabas Jauregui se situará en un punto de partida idéntico al de los otros, pero manifestará una extraordinaria y tensionada voluntad de vivir 
devenida en poder, que lo individualizará aun cuando haya de sucumbir en la lucha por la vida:

Porque un hombre debe recibir, de vez en cuando, señales procedentes de algún lugar que le indiquen que lo está haciendo bastante bien, con arreglo a lo que de él se esperaba, y que se puedan considerar como una especie de premio a su labor como hombre. Todos las necesitamos; de otro modo, aunque siguiéramos adelante, ¿qué otra cosa nos cabe hacer o elegir?, nos moveríamos como muertos, entre sombras y voces acusadoras (Pinilla, 2014: 68).

El encallamiento del carguero de carbón inglés por la galerna es el detonante con que trabar las enconadas relaciones vecinales, pero también familiares en el universo de los Jauregui, por confrontar plurifocalmente las distintas aproximaciones (representaciones) ante la vida, su sentido y finalidad o la capacidad de respuesta de todos los personajes ante la adversidad. Las voces narrativas conducen al lector desde la casona monádica hasta el caserío, compacto en su desafección por los Jauregui. Movimientos centrípetos y centrífugos que desvelan las tensiones brotadas del desencuentro visceral entre los hijos mayores y el padre, o entre éste y su cuñado. Las intrincadas relaciones fraternales revisitan el cainismo dostoievskiano de Los hermanos Karamázov, o de la unamuniana Abel Sánchez, sin obviar la animadversión que los mayores profesan a su progenitor, al estilo del joven Kafka en su Carta al padre (pese a que ni Bruno ni Cosme redactarán línea alguna). La individualidad de Cosme, de Bruno y del tío Pedro desafía íntimamente la autoridad paterna, aunque al fin se sofoque porque carecen todos ellos de la fuerza (barojiana) y determinación de Sabas, cuyo liderazgo de patriarca ancestral resulta incuestionable:

Porque estábamos convencidos de que acabábamos de comenzar algo importante y necesitábamos constituir una unión de fuerzas; si no importante en sí misma, por lo menos en apariencia, considerando lo que teníamos que vencer para llegar a ese algo: el viento y la lluvia, el sueño, el disgusto y hasta nuestros individuales y verdaderos deseos de hacerlo, porque, ¿acaso alguno de nosotros dudó un solo momento de que lo llevaríamos a cabo? (Pinilla, 2014: 83).

Así las cosas, los acontecimientos se precipitan con sencillez. El grupo familiar, compuesto por los cinco hombres y el niño (Sabas, Cosme, Bruno, Pedro, el disminuido Fermín e Ismael) lograrán llegar hasta la playa, pro- 
vistos del gran carro y los bueyes del viejo usurero Lecumberri. El trabajo se resuelve desde la dureza extrema de la lluvia incesante y recia, el frío y la peligrosísima orografía, si bien la coordinación de los Jauregui les hará avanzar mucho más firmemente que al resto, carentes de arreos tan buenos. Sabas pronto se percatará de cómo en lo más recóndito del paraje se amontonan grandes cantidades de carbón protegidas por las rocas, lo que activa de inmediato su sentido no sólo de la supervivencia familiar, también de la ratificación de su autonomía y el triunfo secreto de no doblegarse ante la ley (la ciega del fracaso y la administrativa que la vehicula fatalmente vía decomisos). Fermín, el hijo disminuido para el que parece inspirarse Pinilla en el Benjy de Faulkner o el Lenny de Steinbeck, es enviado al berrocal. Pero la fatiga, o el viento, o un simple golpe de mala suerte harán que se desplome sobre las peñas en su último ascenso, y como Muergo en Sotileza, Fermín se mata durante la ejecución de un trabajo excesivo, abatido telúricamente frente al mar. El accidente marcará el punto de inflexión real en la asunción que sobre voluntad y vida, y voluntad y poder poseen los personajes. La tragedia se desata porque, izado Fermín, cuya cara emerge desfigurada y rota entre las rocas, Sabas no cederá al impulso de trasladarlo de inmediato a la casa para comunicar la fatalidad a la madre y la abuela. La necesidad de sobreponerse al destino ciego de las hormigas atemorizadas, que ya empiezan a abandonar la playa ante los chuzos primeros de los guardias, lo conmina a no marcharse del lugar hasta atestar la carreta de carbón, encastrando las cartolas pese a que Fermín permanece frío y sanguinolento bajo las maderas. Fermín será el último bulto izado que corone los sacos, como ejemplo de cosificación máxima, pues la deshumanización del cadáver parte de Sabas al negar la iconografía clásica de la pietas primitiva en la que todo padre (Eetes ante Apsirto, Príamo ante Héctor) lamenta inconsolable la muerte del hijo.

Luego comenzarán la lucha contra la noche y la llegada del día, la incautación (presentida) del carbón de todos los algorteños, la delación indiscriminada de los unos y los otros si acaso a alguno no se les ha requisado el mineral in situ de madrugada y suscita la envidia de todos los demás, la necesidad por ocultar en un lugar seguro el carro... Se reinicia la lucha por la vida cuando también ya se ha cernido el cainismo, ahora atávico y popular, entre Jaureguis y vecinos. Vemos a Algorta contra Sabas y los suyos, aun cuando el grupo familiar carece de compactación (desconocen en el pueblo que lo único que sutura a los cuatro hombres es un sentido de acatamiento 
de la jerarquía familiar y la energía del padre en conflicto con la abulia y la resignación de los suyos), pero también vemos la voluntad irreductible de Sabas, que resquebraja la fe de Josefa, la madre, en Dios y en él, aunque se restablezca la profesada hacia el segundo al entender que, si ya Fermín no supone una fuerza útil en la casa, al menos el carbón, producto de su muerte, debe convertirse en el objetivo principal de la familia.

Un nuevo descenso al infierno comienza, esta vez tangible por la fetidez de los vertidos y por ratificar el otro, el moral, en el que se halla sumida una familia dividida entre las dos mujeres que velan clandestinamente a Fermín y los hijos, Sabas y su cuñado, que por turnos consiguen desalojar las aguas pestilentes del txitxiposo cavando canalillos que las desparraman por la loma. Infatigable en su capacidad de previsión, Sabas se encarga de cubrirlos con nueva tierra... aunque la negrura hedionda de las campas sea la epifanía tanto de su triunfo como de su regresión a la miseria de todos. El decomisado final del carbón alinea a la familia con las demás y desmitifica a Sabas ante Ismael, que comienza a deconstruir la imagen heroica del padre:

[...] él era "el padre", y yo no podía destruir voluntariamente en un instante todo el caudal de ilusiones y sueños heroicos de mi niñez-adolescencia que había depositado en él, el ídolo que se alza ante todo muchacho con todos los atributos más nobles del animal humano. Algún día, también eso perdí (Pinilla, 2014: 264).

Sabas alcanza, tras la incautación, la dimensión del personaje trágico universal, porque como Edipo, su crecimiento gradual a tenor de la voluntad firme de vivir y poder sufre el revés de fortuna -que no es sino destino-, que lo obliga a asumir de nuevo la ciega voluntad nouménica. Nietzsche superaba los planteamientos de Schopenhauer soslayando el suicidio como desenlace del existencialismo pasivo. El filósofo martillo y dinamita deseaba situar al hombre en una nueva altura que le permitiera rebasar tanto la ataraxia como el compromiso piadoso previos, urgiendo a la íntima transformación que sitúa a leones frente a camellos

Voy a hablaros de las tres transformaciones del espíritu: de cómo el espíritu se transforma en camello, el camello en león, y finalmente el león en niño [...] Mas ahora decidme, hermanos míos: ¿qué es capaz de hacer el niño, que ni siquiera el león haya podido hacer? [...] Sí, hermanos míos, 
para el juego divino del crear se necesita un santo decir "sí": el espíritu lucha ahora por su voluntad propia, el que se retiró del mundo conquista ahora su mundo (Nietzsche, 1982: 61-63).

pero también al desafío y búsqueda de la libertad frente a la obediente resignación segura (y resentida) del esclavo ${ }^{6}$. No hallando razón de ser universal y nouménica, pero tampoco fenoménica, Nietzsche invitará a todo hombre a que busque íntimamente la verdadera motivación vital (y orteguiana) en su yo más esencial. Puro vitalismo, que es voluntad de poder (en modo alguno autoridad) para consigo mismo, subrayando la (hermosa) potencialidad hilemórfica que verbo y sustantivo contienen. Sabas así lo siente (el poder) y así la piensa (la voluntad), en profunda identidad unamuniana («hay que pensar el sentimiento y sentir el pensamiento»), exclamando que:

Es necesario resistirlo todo. Es necesario luchar hasta contra la misma muerte, no solo con actos, sino también con pensamientos; sin abandonarlo todo: deseos, esperanzas y lágrimas a esos actos, olvidándonos del pensamiento, pues éste debe tomar la espada y retar, y ordenar la realización de esos actos salvadores, que siempre fueron cumplidos con la fatalidad de conocer lo único que se desconocía de ellos: si merecía la pena haberlos hecho, suponiendo que el desenlace estaba ya previsto de antemano por Él. Debe tomar la espada y retar, porque el final sólo se escribe con esos actos (Pinilla, 2014: 200).

El estado inmediatamente posterior (y definitivo) consistirá en la metamorfosis en superhombre nuevo, capaz de redefinir su existencia y liberarla del sentimiento trágico de la vida unamuniano por haber encontrado en sí el motor inalienable de la vida, que es la vida misma consumada. Sabas es, por tanto, el personaje que transita por los dos primeros estadios simbólicos, aunque haya de sufrir el revés de fortuna definitivo que lo supedite inexorablemente a la condición de hormiga-camello (contra su paradójica voluntad), pues el delito mayor del hombre es haber nacido sin el privilegio suäve ni la excepción principal que supone ser plenamente libre.

6 «La rebelión de los esclavos en la moral empieza cuando el resentimiento mismo se torna él mismo creador y da a luz valores: el resentimiento de los seres a los que les está negada la auténtica reacción, la de las obras, y que solamente pueden compensar ese déficit con una venganza imaginaria. Mientras que toda moral noble surge de un triunfante decirse "sí" a sí mismo, la moral de los esclavos dice de antemano "no" a todo, "fuera" a cualquier cosa "diferente", a todo "no yo", y este "no" es su obra creadora. Precisamente esta inversión de la mirada que pone los valores [...] forma parte específicamente del resentimiento. Para surgir, la moral de los esclavos necesita primero un mundo contrario y exterior» (Nietzsche, 2010: 18). 


\section{DEL FATUM TRÁGICAMENTE CIEGO (O DEL NOÚMENOS MILENARIO)}

A la resignación desafiada, pero irremplazable como pilar temático de Las ciegas hormigas, suma Ramiro Pinilla metódicamente el ensamblaje de la tragedia clásica, tan apegada a la trayectoria misma de Nietzsche. La tragedia griega, que se convierte en uno de los grandes asuntos sobre los que reflexiona y ensaya el filósofo, se superpone hábil y contundentemente en la novela, actualizando sus premisas inmanentes a instancias de la idiosincrasia de Algorta. Si al héroe trágico sobre el que bascula ésta debía admirársele de rodillas (así lo señalaba Valle Inclán) para que el efecto de su agigantamiento fuera tan enorme como la seguridad en el espectador de su imposible imitación, a Sabas corresponde este papel en su doble dimensión: la folclórica ${ }^{7}$-como depositario secular de un carácter funcional, predeterminado y ecuménico- y la visual -en cuanto a contemplación por parte de Ismael-. Sabas Jauregui se revela como nuevo Hércules, con su fuerza física y moral indestructible, con una fe en sí mismo inquebrantable:

Hay pocos hombres que tengan fe en sí mismos, y, entre este corto número, [...] otros se ven obligados a adquirirla; todo lo bueno, lo sólido, lo grande que hacen, comienza por ser un argumento contra el escéptico que en ellos reside; es menester convencerle y persuadirle, y para ello casi se necesita genio [...] son los más exigentes consigo mismos (Nietzsche, 2003: 157).

espejo meticuloso al fin del héroe en el trabajo de limpiar las cuadras de Augías desviando los cauces del Alfeo y el Peneo, análogo en todo a evacuar la inmundicia del txitxiposo. Ni el cansancio extremo, ni la falta de sueño durante días consecutivos parecen quebrantar la fortaleza de Sabas Jaure-

7 Northrop Frye distingue diferentes tipologías de personajes principales narrativos, atendiendo bien a su filiación con el relato folclórico, entre los que sitúa la épica y el romance (independientemente de la cronología de este último), bien con la novela como género moderno. Dentro de la categoría del personaje folclórico o popular, milenario, universal, traslaticio diacrónica y diatópicamente, halla cabida el héroe, del que indica: «Si es superior en grado a los demás hombres y al propio medio ambiente, el héroe [...] cuyas acciones son maravillosas, [...] él mismo se identifica como ser humano. El héroe [...] se mueve en un mundo en el cual las leyes ordinarias de la naturaleza quedan ligeramente suspendidas: prodigios de valor y tenacidad, que para nosotros no serían naturales, sí lo son para él; y armas encantadas, animales que hablan, ogros y brujas terroríficos, así como talismanes de milagroso poder, nada de ello viola ley alguna de probabilidad una vez que se han establecido los postulados del romance. [...] Si no es superior ni a los demás hombres ni al propio medio ambiente, el héroe es uno de nosotros: respondemos a un sentido de común humanidad y exigimos del poeta los mismos cánones de probabilidad que descubrimos en nuestra propia experiencia. Esto nos proporciona al héroe del modo mimético bajo [...]» (Northrop Frye, 1977: 54). 
gui, que al tiempo también posee la audacia de Ulises al prever los pasos que darán el teniente y Lecumberri, anticipándoseles. El héroe trágico traía aparejada la condición de su hybris, la pasión desmesurada dedicada a la consecución de su objetivo, con independencia de que las pulsiones ajenas pudieran entrar en conflicto con la propia. Éstas respondían inexorables al criterio de prudencia y virtud, y se veían canalizadas por los personajes contrapuntísticos al héroe, bien fueran deuteragonistas, bien el propio coro y su corifeo como voz singularizada, no de otra manera ocurre en Edipo, Antígona o Electra. La nula restricción de la pasión de Sabas, que es desafío al destino de la hormiga, se confrontará con la areté morigerada de Josefa, Bruno y Cosme, pero sobre todo, de Pedro, escandalizado ante la conducta impulsiva y firme de su cuñado, máxime cuando media el cadáver insepulto de Fermín.

Se despliega entonces la catábasis, la bajada al infierno de la (razonable) incomprensión familiar sahumada por la pestilencia del pozo ciego, que desencadena la irrupción del resto de elementos trágicos significativos. Así, el coro, que contraviene las decisiones impetuosas y nunca sometidas a reflexión alguna por el héroe, aparecerá alojado en Josefa y sus hijos, aun cuando sólo sea conocedor de ello el lector, no Sabas. Y Pedro, horrorizado y enfebrecido por el alcohol, irrumpirá en la cuadra con una carcajada dionisíaca, cerrando un cuadro conmovedor dada la vulnerabilidad consciente de personaje derrotado en su calidad de exarconte 8 . El fatum se ha venido cerniendo desde la predeterminación de la adversidad que condena todo esfuerzo a no dar fruto. Sojuzga la individualidad o el libre albedrío al sino, dicotomía sobre la que se concentran las fuerzas enfrentadas en Las ciegas hormigas. El

8 En el origen de la tragedia griega se señala, tanto por Aristóteles en su Poética como por Nietzsche en El nacimiento de la tragedia (1872), que es el grupo o coro el artífice de la declamación salmodiada de los primeros versos consagrados a Dionisos. El tratamiento colectivo o gregario que inicialmente requirieron los metros para su ejecución debió de implicar, aproximadamente, un número impar de integrantes (entre once y quince) que, a su vez, recibieron el nombre de coreutas. Sin embargo, la ampliación ulterior de la extensión o duración de los versos del ditirambo exigió la modificación funcional del coro, de modo que uno de aquellos coreutas abandonó circunstancialmente sus funciones como tal para individualizarse y distinguirse del resto de los miembros. Esta figura primitiva diferenciada, que pronto asume como responsabilidad la salmodia de los ditirambos más relevantes a la espera del recitado unánime de otros tantos por parte del resto de coreutas y más tarde -ya con los grandes trágicos Esquilo y Sófocles- la apelación directa al héroe desde la mesura y la contención recibirá el nombre de corifeo o exarconte. Pedro actuará en calidad de corifeo ante Sabas en el txitxiposo, instalándose en esta última línea de sentido constructivo de la tragedia clásica. Frente a la desmesura de las pulsiones del héroe trágico o hybris que también es perceptible en Sabas, se yerguen la virtud y la prudencia (aretê) del corifeo o exarconte que es Pedro en Las ciegas hormigas, pues insta a su cuñado a que reflexione y razone. Ambas nociones, hybris y areté, establecían el equilibrio escénico y catártico de la tragedia griega, actuando como mutuos contrapesos. 
destino ha alojado a los de Algorta, todos sin excepción alguna, en el inmovilismo milenario que es prueba universal de la impotencia humana. Porque el ecumenismo no entra en conflicto con la concreción de los hechos en la familia de Sabas, antes al contrario, permite a Pinilla enlazar con las maltrechas estirpes castigadas de los Labdácidas, Atridas o Helíades aunque deba trocarlas ahora por los Jauregui. Como Lábdaco, Layo, Edipo, Antígona, Polinices y Eteocles, Agamenón, Electra, Orestes, o Medea, ejecutora de sus propios hijos, también los Jauregui están condenados a la reiteración cíclica del castigo que los proscribe de toda libertad, en un tiempo caído o eternidad negativa que, gravitando sobre todos ellos, los convierte en seres mecánicos, inorgánicos, vegetales como el carbón mismo, autómatas programados para sufrir ininterrumpidamente, aherrojados a la no progresión, la fosilización y la usurpación de toda coyuntura, oportunidad (o clásica peripecia) nouménica que les inste a sobreponerse. Las maldiciones dirigidas contra los viejos Lábdaco y Atreo, contra las hijas del Sol lastrarán a todos los descendientes de cada uno de ellos, víctimas inocentes de un error inicial que no ha de saldarse nunca, como tampoco habrá de ser saldada la falta de los Jauregui (y de toda Algorta), no siendo ésta otra que, como ya se apuntara, el "delito de nacer" existencial y calderoniano.

Como Edipo, como Antígona u Orestes, como Hamlet o Willy Loman, el viajante de Miller, Sabas se incorpora al censo de personajes perseguidos por el destino devastador e irrecusable de sus linajes. Aspectos funcionales de la tragedia clásica como la anagnórisis o las hamartías ${ }^{9}$ concurren también bajo las trazas del limo fétido que delata a Sabas y permite -como en Tebas- la reconstrucción secuencial, causal y consecutiva de los hechos. Queda restañar la que sería justicia de los dioses (teodicea) quebrantada por Sabas: no tanto la muerte

\footnotetext{
9 Ambos conceptos resultan vertebrales en la construcción de toda tragedia clásica, siendo recuperados también por los grandes trágicos del Siglo de Oro con Shakespeare como principal dramaturgo. Aristóte-

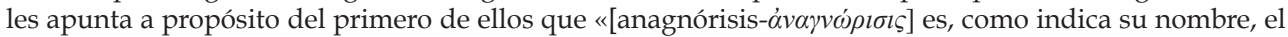
paso de la ignorancia al conocimiento, provocando además amistad u odio en aquello que están destinados a la felicidad o a la desdicha. El reconocimiento más efectista es el que se produce simultáneamente con la peripecia, como sucede, por ejemplo, en el Edipo. Hay también otras clases de reconocimiento: y, en efecto, es posible que el fenómeno descrito ocurra a la vista de objetos inanimados y triviales como también puede ser objeto de reconocimiento saber si alguien ha hecho o no alguna cosa. [...] Pero, puesto que el reconocimiento es reconocimiento de personas, puede ocurrir que sea sólo una persona la que reconoce a la otra, porque la identidad de aquélla es evidente, en otros casos, uno y otro se reconocen mutuamente» (Aristóteles, 1997: 38-39). Hamartía ( $\mu \alpha \rho \tau i \alpha)$ ), también denominado genéricamente por Aristóteles como "lo patético" es, a su vez, «una acción destructora y que provoca reacciones dolorosas, como por ejemplo, la muerte en escena, los dolores, heridas y otros hechos parecidos» (Aristóteles, 1997: 39).
} 
violenta de Fermín como la desaprensión paterna ante su cadáver podrá quedar impune. La transgresión de Sabas consistió en transvalorar carbón por vida y el castigo incidirá en reparar tal resquebrajamiento. El carbón no habrá de rentar, devuelto a la Comandancia. Todo ello revelará a Ismael la resignación consciente que, en lo sucesivo, deberá ejercer de pauta en su vida. La moderna resiliencia del niño es vieja abnegación si en la lucha por la vida se está en el bando vulnerable. Pero no obsta que se pueda admirar ciegamente a quienes, en algún momento, hayan alcanzado la liberación plena del niño nietzscheano, que el Negro escurridizo y telúrico simboliza en Algorta. Porque:

[...] cuando, después de un día de trabajo, te eches en tu cama pensando en la dura tarea que te espera al día siguiente (no solamente de trabajo, sino también de contención de la mente y de la carne y, sobre todo, de inútil lucha feroz por mantener incólumes tus convicciones ante el fárrago de palabras e ideas que surgen de libros, diarios, radio y estrados, tratando de destruir tu individualidad y empotrarte en la gran bola masiva que en su loco giro acabará absorbiéndote hacia su interior y despojándote de lo único digno), y tus ojos, en la oscuridad, miren hacia el techo, sin ver, te acordarás de él y lo sabrás nadando invulnerable y te sentirás mejor [...] porque no podríamos arrebatarle más que su carne. Él perdería lo que no tiene precio para ningún ser viviente y nosotros sólo ganaríamos su carne (Pinilla, 2014: 307).

Sólo así consigue Ismael su iniciática catarsis. Obviará desde ahora preguntarse para qué han sido creados así.

\section{DE HORMIGAS, MULAS Y HOMBRES. CONCLUSIÓN}

El fabulario contemporáneo presente en títulos como el steinbeckiano De ratones y hombres (1937), el Bestiario (1951) cortazariano o el propio Las ciegas hormigas de Pinilla parece conferir a los animales más sencillos y humildes toda una carga simbólica en cuanto a significación en sus textos, incardinada en pautas abrumadoramente existenciales. Ratones, hormigas y la mula machadiana y vieja de los ojos vendados ${ }^{10}$ se convierten en metonimias y símbo-

\footnotetext{
10 "La noria": [...] El agua cantaba | su copla plebeya | en los cangilones | de la noria lenta. | Soñaba la mula | ipobre mula vieja!, | al compás de sombra | que en el agua suena. | [...] Yo no sé qué noble, | divino poeta, | unió a la amargura | de la eterna rueda | la dulce armonía | del agua que sueña, | y vendó tus ojos, | ipobre mula vieja!... Soledades, galerías y otros poemas (1907).
} 
los de una isotopía extensa y próxima en el tiempo cuyo objetivo es redundar en la noción clásica -y por tanto universal- de una circularidad temporal inquebrantable que instala al hombre, trasunto de roedores, insectos y bestia de carga, en un eterno presente cuyo tiempo se ha precipitado hacia la eternidad negativa de Cioran. Imposible de modificar esta condición durativa, convertido el tiempo en negación de sí mismo y consecuente durée, el hombre es condenado a la reiteración de hechos absurdos de por vida, porque la abrogación de toda diacronía no responde sino a la perpetuación de las fuerzas nouménicas e irracionales que rigen la realidad. Es ésta una realidad inconmensurable, infinita y ciega, autónoma y autotélica, que trasciende al hombre y a la que el hombre ha pretendido sojuzgar fenoménicamente. Frente al arbitrio per se de "lo que no conocemos y apenas sospechamos"11, Schopenhauer situaría la voluntad humana irrevocable de representar este mismo noúmeno, deviniendo realidad cognoscible, descifrada y funcional, o al menos, poseedora de una finalidad última. Sin embargo, la toma de consciencia del hombre de la invariabilidad de las primeras y la desposesión final que éstas llevan a cabo del objeto último de toda existencia vuelven a arrojarlo a la comprensión terrible del absurdo y la nada vitales. La ceguera triunfante del noúmeno se trueca, paradójicamente, en ceguera derrotada del hombre, que entiende (o intuye al menos) que su avance lineal en la existencia (en su existencia) y en la Historia no es sino falaz. Como la mula de ojos vendados que cree caminar hacia delante, como las hormigas ciegas que reiteran sus trabajos arduos, confiadas en la consecución de un objetivo inexistente, el hombre se engaña recogiendo el carbón feliz que le es arrebatado invariablemente. Sólo Sabas e Ismael saben, porque han intuido y comprendido, que la única estrategia para sobreponerse a lo inexorable es la conciencia plena de la individualidad inalienable. Aquélla, que, como el niño preconizado por Nietzsche, ignora deliberadamente el sinsentido de todo lo mediato y lo inmediato, y se concentra en la potencialidad propia, la voluntad de ser y el afán de progreso sin otro reconocimiento, sin otra autoridad que la consciencia propia.

\section{REFERENCIAS BIBLIOGRÁFICAS}

Acillona, Mercedes (2015), coord.., Ramiro Pinilla: el mundo entero se llama Arrigunaga, Bilbao, Deusto.

11 “Lo fatal”, Rubén Darío en Cantos de vida y esperanza (1905). 
ArIstóteles, (1997), Poética, Barcelona, Icaria editorial.

Baroja, Pío (1993), El árbol de la ciencia, Madrid, Cátedra.

Calderón de la Barca, Pedro (1985), La vida es sueño, Madrid, Cátedra.

Cioran, Emil (2014), Del inconveniente de haber nacido, Madrid, Taurus.

Clavería, Carlos (1970), Temas de Unamuno, Madrid, Gredos.

Deleuze, Gilles (1986), Nietzsche y la filosofía, Barcelona, Anagrama.

Frye, Northrop (1977), Anatomía de la crítica. Caracas, Monte Ávila Editores C.A.

Nietzsche, Friedrich (1982), Así habló Zarathustra, Barcelona, Orbis.

- (2003), La Gaya Ciencia, Barcelona, El Barquero.

- (2010), La genealogía de la moral. En línea: http:/ /www.biblioteca.org.ar/ libros/211756.pdf. Último acceso el 20-ene-2018.

Ortega y Gasset, José (1943), Prólogo a Veinte años de caza mayor, del Conde de Yebes.

En línea: https://www.unaccyt.org/.../Prologo-a-20-años-de-caza-mayorOrtega-y-Gasset. Último acceso el 25-ene-2018.

Philonenko, Alexis (1988), Schopenhauer. Una filosofía de la tragedia, Barcelona, Anthropos.

Pinilla, Ramiro (2014), Las ciegas hormigas, Barcelona, Tusquets.

SCHOPENHAUER, Arthur (2003), El mundo como voluntad y representación I, traducción, introducción y notas de Pilar López de Santa María.

En línea: http:/ / wwwserbal.pntic.mec.es/AParteRei/fuster72.pdf. Último acceso el 15-ene-2018.

Unamuno, Miguel, (1999). Del sentimiento trágico de la vida, Madrid, Alianza editorial. 


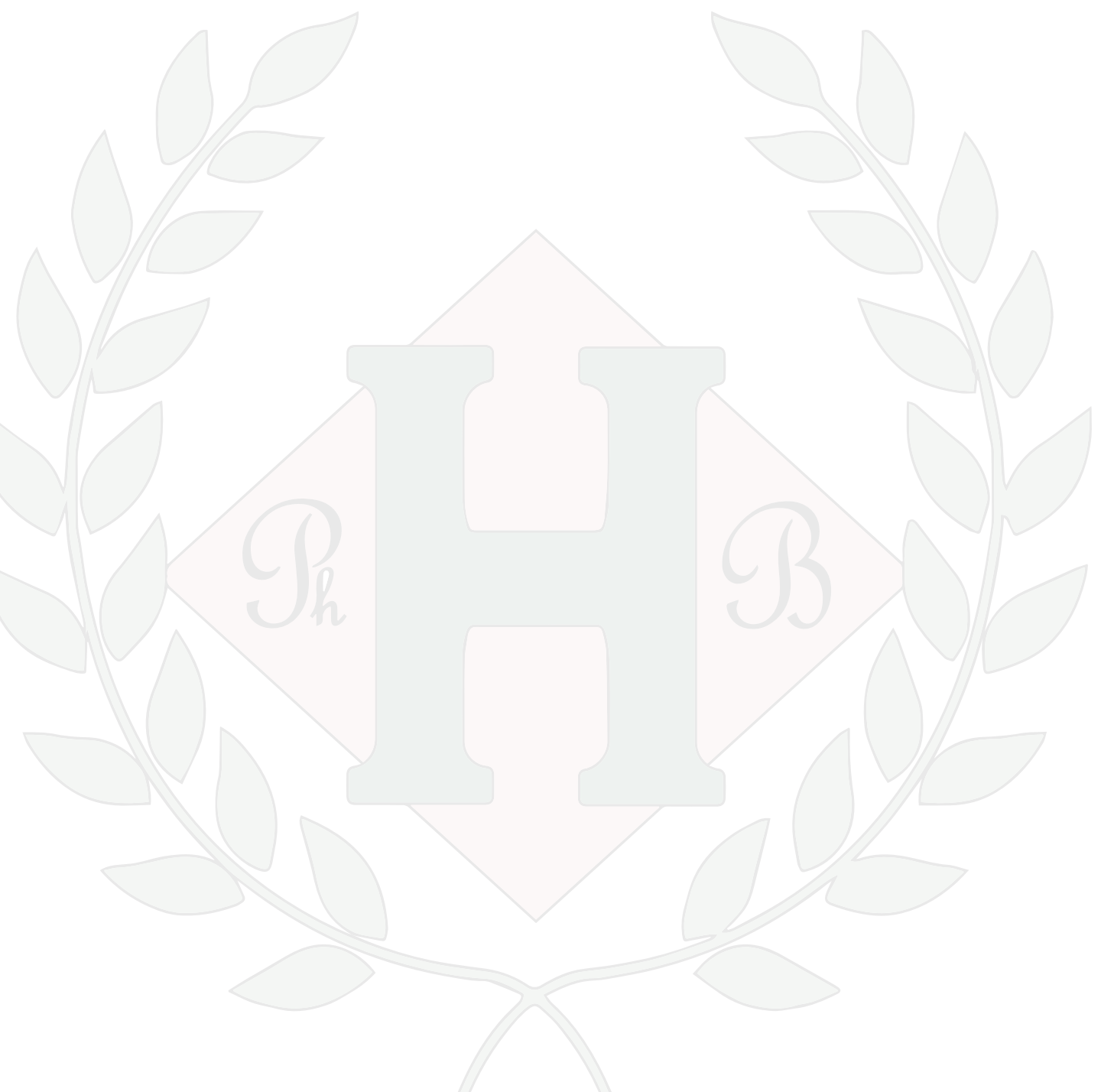

